\title{
APPLICATION OF INTERMEDIATE DOCUMENT MESSAGE IN THE PROCESS OF ENTERPRISE RESOURCE PLANNING AND MANUFACTURING EXECUTING SYSTEM INTEGRATION
}

\author{
Simon Oman \\ Polycom Škofja Loka, Poljane, Slovenia \\ E-mail: simon.oman@polycom.si
}

\begin{abstract}
It is well established that the ERP systems represent transaction processing systems and are thus as such not suitable for controlling and monitoring the production in real time. Hence, a comprehensive solution proves the most efficient, ensuring connection between the process level, representing collection of actual measurements (cycle time, temperature, pressure, etc.), and business level which facilitates decision-making. The present paper focuses on the development of a comprehensive integration between the Enterprise Resource Planning (ERP) and Manufacturing Executing System (MES) system, which enables data refreshing in real time irrespective as to which the information system the change has been triggered in. Integration is performed on the basis of the Intermediate Document (IDoc) message, which enables data exchange between two databases. A new model of numbering is introduced for following cost-effectiveness of production activities. Said model allows for an efficient inspection and overview of the entire process from the design to implementation.
\end{abstract}

Key words. enterprise resource planning, manufacturing executing system, intermediate document technology, integration.

\section{Introduction}

Although the experts define a number of different integrations (Kul'ga and Gil'fanov, 2008), only a few of such integrations prove well implemented in practice. The literature (e.g. Themistocleous et al., 2001, Tarn, et al., 2002, Gulledge, 2006, Mertins et al., 2008, Metaxiotis, 2009) provides evidence that cooperation between individual departments is regarded as integration. The word integration is mostly used in the literature on business systems (Gulledge, 2006), while individuals define the word differently. Generally, there is an agreement dictating that integration represents a joint operation of different applications (Gulledge, 2006). Pursuant to the publication of Oracle Corporation (2002) a clear appeal was launched that the integration is represented by two notions, namely "Big I" and "Little I". Integration "Big I" indicates that all relevant data pertinent to business processes is located on one place or is processed in the same software application. Application modules thus reflect updating of information without any complex interfaces. In such a way the information is only stored once and is available online (Gulledge, 2006) to all business processes which actually indicates the modularity of the ERP (Enterprise Resource Planning) system. The second alternative, i.e. "Little I", results from the fact that many companies do not want to integrate all their data in a common business information system due to different reasons. Integration "Little I" actually embodies a more relevant form of integration which may be named system integration (Gulledge, 2006) whereat 
PROBLEMS

OF MANAGEMENT

IN THE $21^{\text {st }}$ CENTURY

Volume 2, 2011

142

focus is made on the implementation of business processes. Many forms of integrations were acknowledged as described in more details by Thomas Gulledge in his research:

- integration between two points,

- integration between two bases,

- integration of data warehouse,

- integration between companies,

- integration of applications.

A review of the existing literature on examined issue taking into consideration different sources represents an important step of our research. This is followed by an analysis of relevant facts where focus is made on the review of concepts (conceptual models) and standards provided for ensuring a comprehensive (integrated) information support of a manufacturing company. Models, standards, good praxis and technical solutions for the integration of business and production information systems represent the core of our analysis. A research follows, representing a concept development of interconnection of two databases which in the concrete environment ensures efficient and reliable connection between business and process flow of information. With the aim of implementing the concept the ERP system Microsoft Dynamics NAV and MES system HYDRA are applied. Finally, conclusions and recommendations for further work are presented. Developed concept enables simultaneous planning with the help of interactive planning table, which in praxis means that different departments (e.g. production, tool-making department, technology, maintenance department) use joint planning table, while at the same time each department independently plans its own resources. The solution enables a transparent solving of eventual conflicts arising during the planning process of production. Consequently, a new thinking dimension is brought into companies. Such dimension is based on the fact that a company no longer deals with a hierarchal decision-making yet focuses on the buyer as its customer.

\section{Literature Framework}

\section{Development of Information Systems to Support Business Processes}

In introducing information systems, companies tend to adopt different approaches to integrations. At the same time the said companies strive towards introducing information technology through logistic processes, since they were focusing on the business process integration from the mid to the end of the 1990s. Development of the ERP systems has undergone different development stages (Figure 1) and nowadays boasts closer and closer integration. As indicated by the authors (Marnewick and Labuschagne, 2005) they recognised also the fifth stage (the so-called ERP II or extended ERP) in the development of the ERP system. At the same time, new development solutions of the ERP systems enable diversification of business process and thus open new ERP III architecture (Stadtler, 2004). 


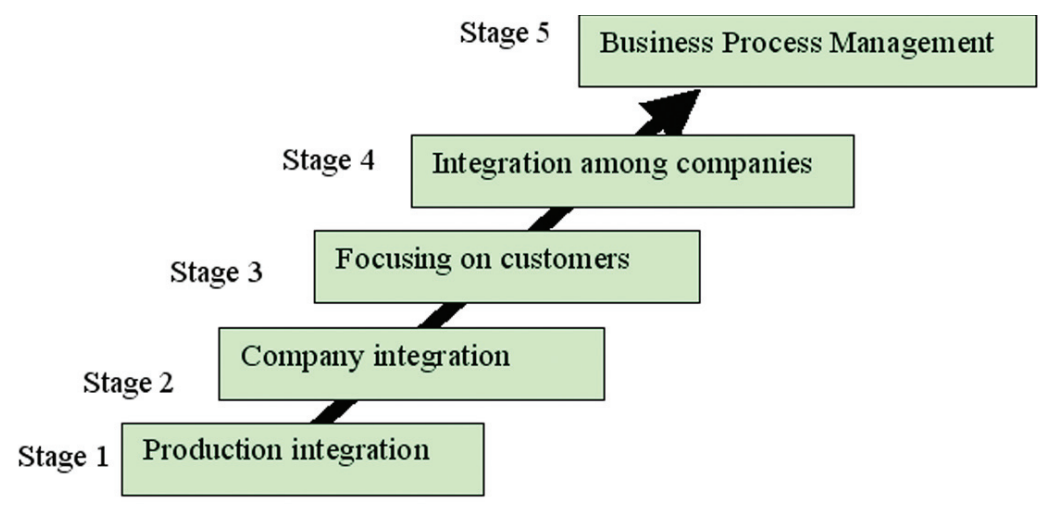

Figure 1: Stages of ERP system development (Source: Sammon, Adam 2005).

The authors (Kakouris and Polychronopoulos, 2005; Beheshti, 2006; Djassemi, 2009) state that most of the production companies boast an implemented module of the ERP system; however, a lot of them fail to have an implemented production module for monitoring and controlling the production given that the precondition for monitoring the production requires reading of the attributes (energy, temperature, pressure, and suchlike) from different devices and instruments, as well as data exchange between the control and the system of Supervision Control Alarm Data Acquisitions (SCADA). The ERP II system contains six elements which integrate business, applicative and technological strategy (Møller, 2005), namely:

- its role,

- its business domain,

- system architectures which support these processes,

- required types of processes within envisaged tasks,

- envisaged tasks within these domains,

- the method of monitoring data within these architectures.

On the basis of proposed strategies, it may be established that the exceptions of the system architectures of the ERP II represent nothing else but the traditional ERP. Generally, it may be concluded that the ERP II represents a modular scheme which includes e-business and cooperation within the supply chain. Actually, nowadays almost all companies adopt the concept of the ERP II system; some companies have adopted the system fully, others adopted the ERP II system only partially. In all the aforementioned, the Business Intelligence (BI) represents one of the examples of the ERP II, which facilitates different business analyses of data gathered in the information system and simple preparation and conveying of reports. Business Intelligence is a tool for Extended Mark-up Language (XML) represents another example with which its strategy bases on electronic business. The consequences of all fast-growing technologies are samples of generic applicative architectures (Møller, 2005). The fundamental framework of the ERP II, demonstrated in Picture 2 encompasses four stages (Møller, 2005):

- basic components,

- central components,

- business components,

- co-operation components. 


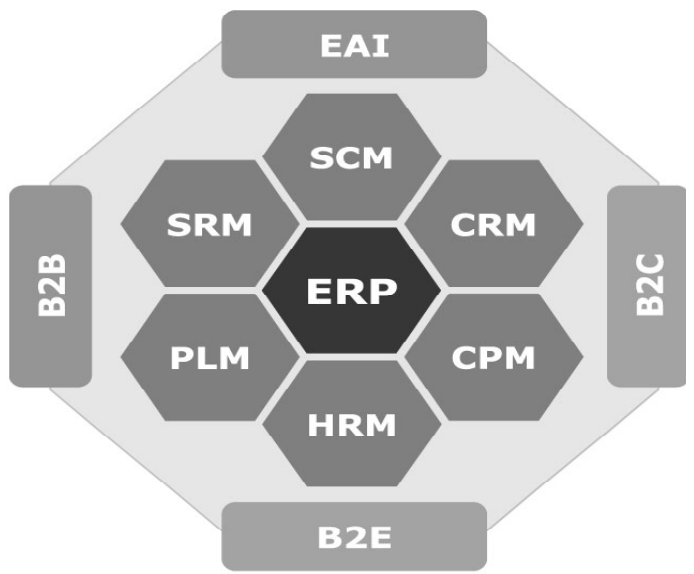

Figure 2: Fundamental framework of the ERP II system (Source: Møller, 2005).

Basic components represent the fundamental level of the ERP II system and contain its basic architecture. One of the basic components is an integrated database which does not need to be standardized yet it should be dispersed (Møller, 2005). By spreading the base, dispersed systems appear, thus enabling modularity and indicate a computer integrated company. Applicative tool represents the second component of the fundamental level.

Central components envisage process level, reflecting business events in the past and represent transactional system. The ERP II system is based on the online architectures which are opened and modular and, at the same time, suitable for dispersed online services. In fact, the traditional ERP is a central component of the ERP II tool since the usual ERP modules, such as finances, sales, purchase, logistics, production and human resources, still represent the backbone of the ERP system, including additional modules intended for quality, project management and maintenance (Møller, 2005). The ERP II system is based on (Møller, 2005) Business Process Management (BMP) and thus represents technology helping to model, automate, manage and optimise business processes.

Business components rest upon the analytical level and increase the functionality of the central ERP system with the purpose of ensuring support in decision-making process. Business components presented here below do not necessarily need to be aligned with the integrated base (Møller, 2005):

- Supply Chain Management (SCM),

- Customer Relationship Management (CRM),

- Supplier Relationship Management (SRM),

- Product Lifecycle Management (PLM),

- Employee Lifecycle Management (ELM).

Co-operation components represent the ERP II portal intended for electronic business (Møller, 2005). Electronic business enables companies to integrate their internal and external processes more efficiently and flexibly. The introduction of electronic business into a company does not only suggest the purchase of information and communication technology but also a number of new changes in its performance. Electronic business influences the development of new business models, reform of business processes and suchlike. In reality, systems for Supply Chain Management and Customer Relationship Management are formed.

Changes in the business management as a reflection of the introduction of electronic 
Simon OMAN. Application of Intermediate Document Message in the Process of Enterprise Resource Planning and Manufacturing Executing System Integration

business have resulted in new business models. The model of electronic business is a business method which helps an organisation to achieve value added on the basis of the internet. Models

PROBLEMS OF MANAGEMENT IN THE $21^{\text {st }}$ CENTURY Volume 2, 2011 of electronic business may be divided in many different ways. Professional literature suggests division pursuant to the approaches, objectives and purposes of electronic models (Stadtler, 2004). Co-operation with suppliers and business partners is becoming closer which represents integration between the ERP II system and external factors (Møller, 2005) such as:

- Business-to-Consumer (B2C),

- Business-to-Business (B2B),

- Business-to-Employee (B2E),

- Enterprise Application Integration (EAI).

In industrial manufacturing the companies are surrounded with numerous software solutions classified pursuant to their functionality (Djassemi, 2009). Suppliers and purchasers represent an external implementation of processes which in a way depend on internal processes and include different fields as to their tasks. Generally, the internal processes may be divided into technical and commercial (Stadtler, 2004), or organisational-planning and technical (Campos and Miguez, 2011), which rest upon mutual co-operation (Figure 3).

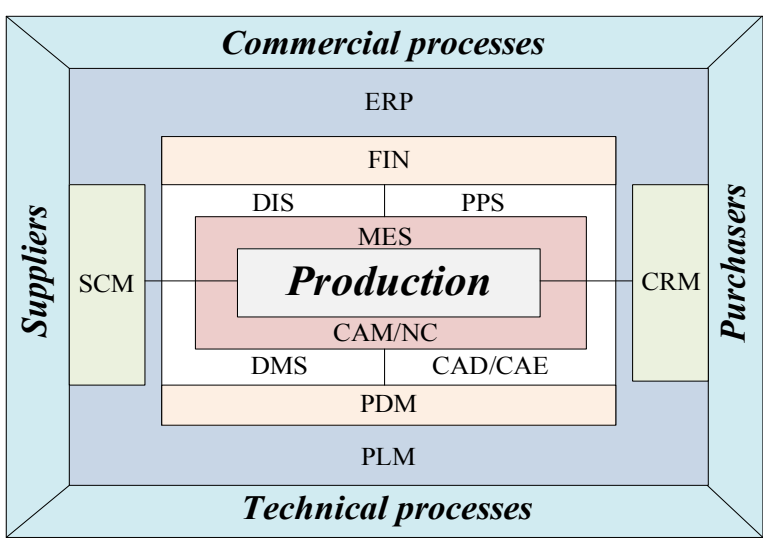

Abbreviation legend:

CAD - Computer Aided Design

CAE - Computer Assisted Engineering

CAM - Computer Aided Manufacturing

DIS - Distribution

DMS - Document Management System

ERP - Enterprise Resource Planning

FIN - Finance

MES - Manufacturing Execution System

$\mathrm{NC}$ - Numerical Control

PDM - Product Data Management

PLM - Product Lifecycle Management

PPS - Production Planning and Scheduling

\section{Figure 3: Co-operation of applicative fields within a company (Source: Kletti,} 2005, pp. 67).

\section{Reference Models and Standards for Integrating the ERP and MES Systems}

The function of integration between business and production processes is represented by applicative interfaces. Business information systems (ERP) ensure comprehensive information on managing finances, sales, purchase, warehouse and material flow, production and human resources and supports e-commerce. State-of-the-art business information system (ERP) is oriented primarily towards global planning, business processes and implementation of processes throughout the entire supply chain (Barry et al., 1998; Hori et al., 1999; Zhou et al., 2005). At the same time these same authors point out two functional areas which need to ensure integration in the manufacturing environment. 


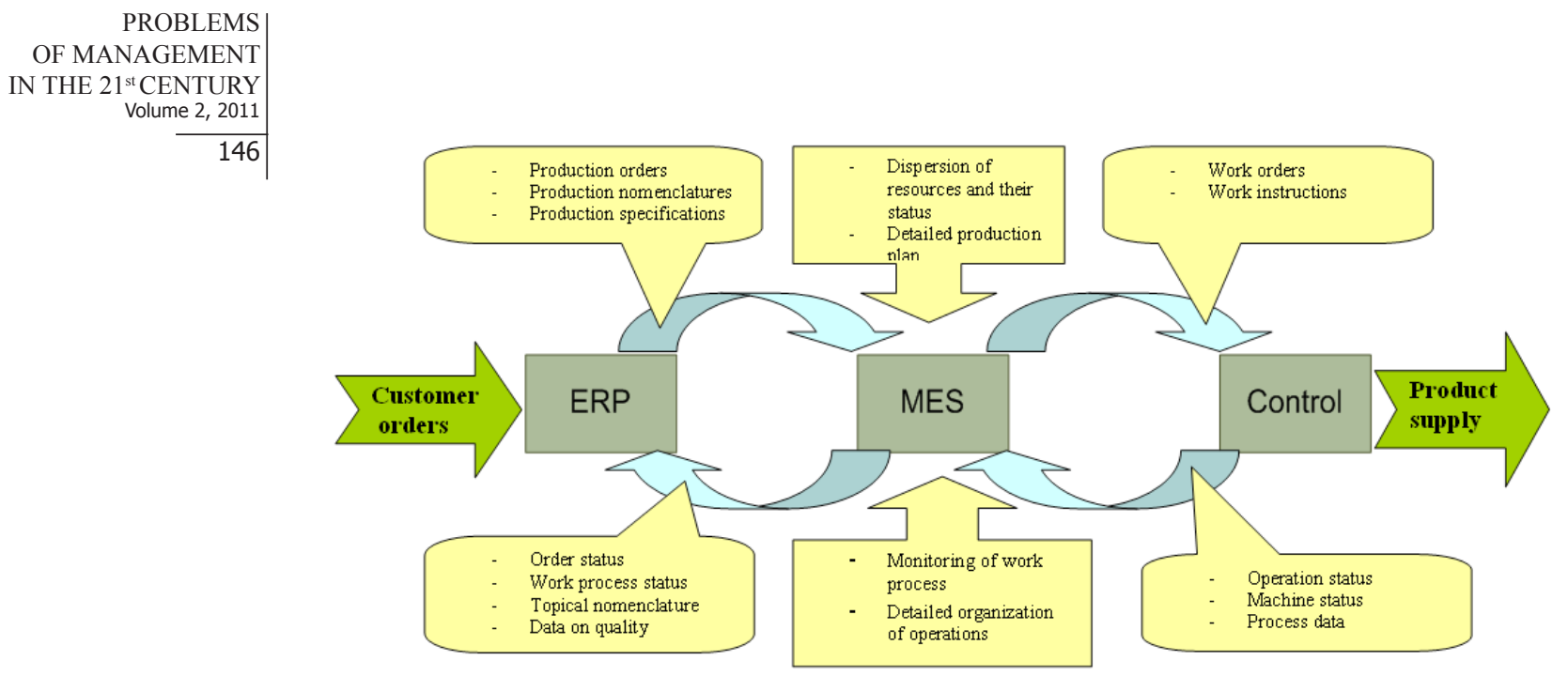

Figure 4: Information flow in integrated MES system (Source: Zhou et al.,
2005).

As to the content of information, business and process information are integrated in a real manufacturing environment; however, this information needs to be interconnected via a system which is not only an on-line information system but it also needs to provide feedback and enable control over the production. The system focused on gathering information on planning production resources, ensuring quality and providing the required workforce is called Manufacturing Execution System (MES). A quality integrated MES system leads to a competitive advantage in the manufacturing environment and facilitates tactical decisions to be made in real time. In different publications, the authors believe that the integrated MES system (Figure 4) encompasses many functions and tasks (Barry et al., 1998; Hori et al., 1999; Zhou et al., 2005):

- organisation of resources and their status,

- detailed organisation of operations,

- product organisation,

- maintenance activities,

- process management,

- monitoring of products and their family of products.

\section{Requirements of the ERP and MES Environment}

In the ERP environment, such as what used to be the SAP, it was recognised at the beginning of 1990 that a simple system should be launched onto the market which should provide feedback and should serve as nothing else but a data gatherer (Liu and Barrar, 2009). The system was named Production Data Acquisition (PDA) and later the MES system. Frequently these systems contained or contain more or less complex feedback units which are combined with an applicative interface. Consequently, a subordinated system was designed with the purpose of moving closer to the manufacturing environment and thus improving the quality and reliability of the process.

In order to move closer to the manufacturing process, a transparent review of the actual situation needs to be carried out on the basis of information provided by the ERP system (delivery date, final quantity, scheduled cycle, production time, setting time and suchlike) while the results need to be reported back to the ERP. These results trigger activities which help us 
answer the question on information reliability. Technically, this is represented with information technology which ensures information flow from the ERP into the MES system and vice versa. At the same time it proves important that the ERP and MES systems are separated in order to prevent eventual errors of results. The MES system needs to be flexible enough to enable adjustability of differently managed organisations and, at the same time, to support different types of production; however, it still needs to be sufficiently uniform to ensure integration of the central ERP system. To sum up, it is important to ensure organisation of production or departments in the manner where production may be monitored in one location in real time when other functionalities are not required or only the functionality of the ERP system is available (Harjunkoski et al., 2009).

\section{Integration of the ERP and MES Systems}

Generally, integration of the ERP and MES systems represents an exchange of information between two applications, e.g. SAP envisages exchange of data between the Production Planning (PP) and the MES system. As emphasised by the author (Liu and Barrar, 2009) the application SAP, for example, ensures individual module or ERP interface which is based on NetWeaver technology where the MES system sends obtained data to the ERP system via ERP interface and, at the same time, receives all necessary information for the MES system operation. The same author adds that the applications in the ERP system are connected via applicative interfaces, e.g. mySAP and MES system Hydra. These interfaces provide information exchange between two systems which practically represent a connection between two processes (process and business), which operate completely independently. The umbrella organisation Manufacturing Execution System Association (MESA) has been striving to align a list of consistent MES solutions into a uniform functional system C-MES (collaborative MES).

However, MES does not serve only as an intermediary between the process and business level but also as an integrated hub (Wicks and Dewar, 2007) within a company. Considering the fact that companies have invested substantial funds into the ERP systems and process technology in past years, they now wish to harvest the fruits of their investments. However, the integration gap between business and process information may be observed since the field of computerisation of business processes is becoming ever more important for the companies. In 1990, the organisation Instrumentation Systems Automation Society (ISA) decided to develop a standard which would provide a bridge between business and process functions (Campos and Miguez, 2011). For this purpose ISA S95 standard was developed, which does not represent an automated system between the ERP and MES systems, yet it encompasses methods, working methods, reasoning and communication. The said standard was developed with the purpose of reducing costs and eliminating risks and errors in the development and implementation of interface between the ERP and MES systems. As demonstrated in (Figure 5), standard ISA S95 encompasses a multi-level structure which begins at Level 0 and rises up to Level 4. Functional hierarchical model is presented with two domains, namely business domain which begins at Level 4 and production domain which begins at Level 3 and drops down to Level 0, and which represents physical processes in real time. 
PROBLEMS OF MANAGEMENT IN THE $21^{\text {st }}$ CENTURY Volume 2, 2011

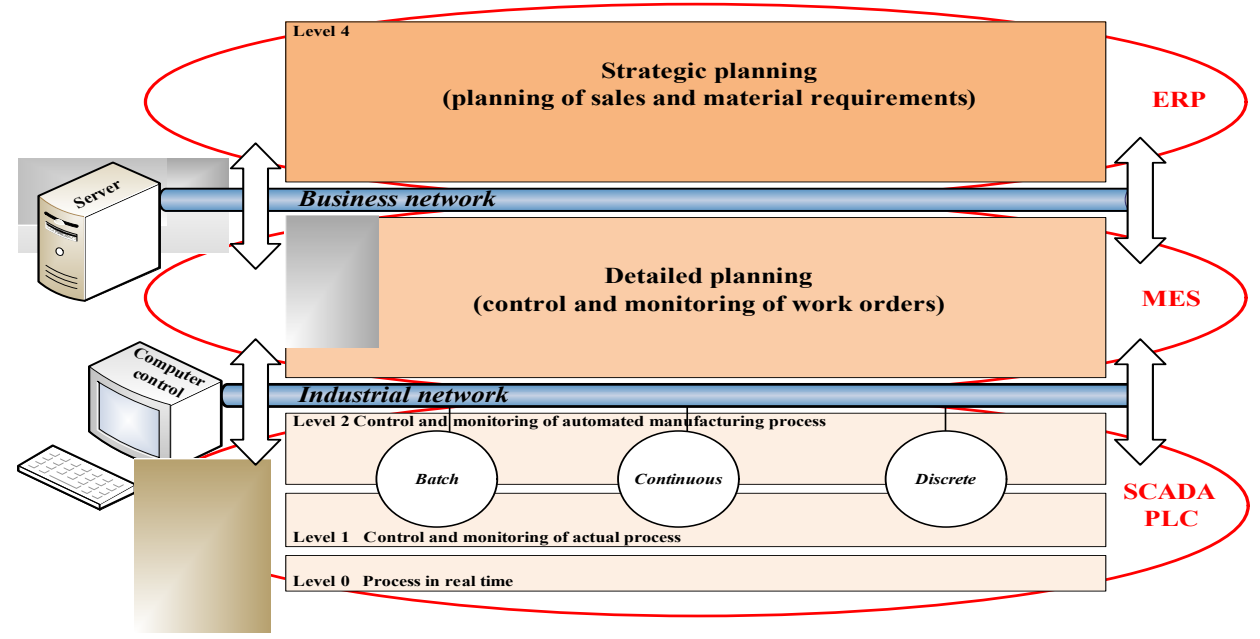

Figure 5: Multi-level functional model according to the ISA S95.

\section{MES as an Integration System}

The researches (Kirsilä et al., 2007; Wicks and Dewar, 2007; Panetto and Molina A., 2008; Zhao et al., 2011) revealed that in process organisation of companies the information technology proves the least developed, the problem being a lack of integration between different non-integrated databases, since process-oriented organisation results in process approach to thinking and orients towards a wider organisation of information, processes and people which are based on integration. Computerisation of business processes requires adequacy of data sources which need to be gathered in a single database available to different applications. On the other hand, constant changes on the market force the producers to reduce prices and provide a high level of flexibility whereby computer and information technologies play an important role by constantly providing new options. Consequently, companies opt for a comprehensive MES system, which enables monitoring and execution of production in real time. It has been established lately that the hierarchical informing of employees does not suffice for an efficient and up-to-date monitoring of production any more; however, it needs to be complimented with tactical decisions made in real time thus breaching the gap between business and process level. In such a way, the companies applying the MES system ensure:

- work order implementation,

- work operations organisation,

- detailed planning and scheduling,

- machinery management,

- process data acquisition,

- efficiency indicators, and suchlike.

The purpose of integration is to improve manufacturing processes and ensure greater transparency of the machinery operation which consequently increases the quality of production lines, since the informatics and automation in manufacturing process connect hardware and software, control of machinery, robotisation, testing, quality monitoring and control, thus enabling the companies to integrate computer automated units. Only a comprehensive MES system provides modularity of the system and, as such, ensures support to monitoring and managing not only mass but also made-to-order production (Zhou et al., 2005). We should 
not, however, forget about the software interface which facilitates close co-operation between the manufacturing environment and business information system. The fact remains that the key to success rests upon computer integrated production oriented pursuant to a strict and well-structured philosophy. Reciprocal functions within the information integrated model are integrated information which represents dispersed systems. Huge amounts of data within a company, i.e. technical and organisational-planning data, result in the use of dispersed systems (Campos and Miguez, 2011). The concept is based on the integration of central technical and production information with a possibility of integrating the data on marketing, orders, maintenance, accountancy and finances, as well as the distribution of products (Patel and Sanyal, 2008).

The underlying significance of data integration is a simultaneous planning and scheduling with the help of an interactive planning table whereby all participants in the production process develop such a plan together. This means that different departments (e.g. manufacturing, tool-making, technology, and maintenance departments) use a common planning table where each department independently plans its resources and thus enables an organised approach to managing production processes within a company. As a result, a company boasts a new dimension which is based on the fact that the company is no longer involved in hierarchical decision-making yet shifts its focus to the purchaser as a customer.

\section{Research}

A great importance in implementing new integration between the ERP and MES system is placed in numerous phases, where each phase represents a completed unit. Activities envisaged within each phase are described on the basis of GAMP (Good Automated Manufacturing Practice) methodology, which has been representing the basis for validation of control systems (Scholten, 2011) for some years now. The initiative for developing the GAMP methodology came from the ISPE (International Society for Pharmaceutical Engineering). One of the known models of the GAMP methodology is the V-model (Figure 6) which clearly indicates that the projects of production information systems contain different phases of introduction.

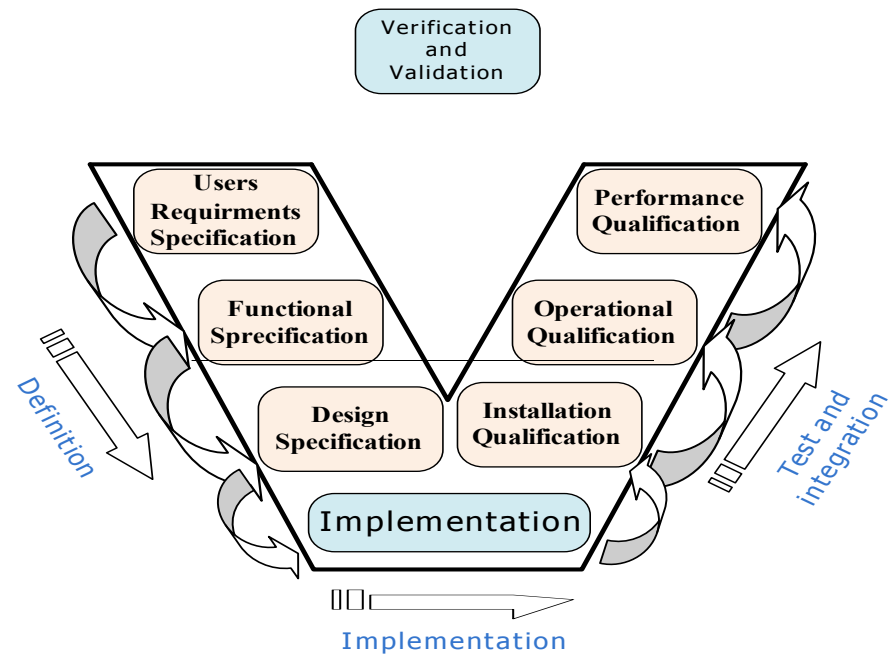

Figure 6: GAMP methodology (V-model).

The ISPE developed the GAMP methodology with the purpose of obtaining an appropriate standard explanation for the concept of GxP (Good x Practice). In introducing the MES system the GxP concept represents GMP (Good Manufacturing Practice), or in other words, general 
PROBLEMS

OF MANAGEMENT

IN THE $21^{\text {st }}$ CENTURY

volume 2, 2011

150

guide to good practice in manufacturing. Functional requirements are identified in the User Requirements Specification (URS) phase, placing importance on traceability of implementation and validation of implemented activities by both the principal as well as the provider. This is followed by Functional Specification (FS), where the operation of final system and its final tasks are described. Design Specification (DS) comprises of a detailed technical description of proposed solution and is indented for people whose task is to build and install the solution.

After the definition of the project is complete, the implementation of the project follows, including both the hardware and software implementation, followed by configuration of the entire developed solution. After the configuration has been completed, this if followed by integration and different phases of testing, which help determine the proficiency of a particular phase. Proficiency of each particular phase is represented by the assessment defined in the project's definition. This means that each phase is tested with regard to prescribed requirements, while verification and validation of each particular phase is performed at the end of testing. It proves extremely important for the Installation Qualification (IQ) phase to meet all necessary specifications as set forth in the Design Specification phase. All hardware and software enabling cooperation with other components need to be provided and installed. At times, the phase of installation assessment is called also the Factory Acceptance Test (FAT). The result of Functional Specification (FS) phase reflects in Operational Qualification (OQ) phase. With the phase the target hardware is verified and validated at the principal's. Such target hardware needs to prove that the system operates on the basis of requirements set forth in the Functional Specification (FS) phase. The process is concluded with the Performance Qualification (PQ) phase which needs to ensure that all requirements set forth in the User Requirements Specification (URS) are successfully implemented in the production information system.

\section{Results of Research}

Due to the complexity of global business operations, organisations need a standardised concept of number series which provides information support in tracking a product throughout its entire life cycle. The fact remains that the information support is the development process brings the development of highly-functional products, which ensure value added and are based on technological knowledge and systematic manufacturing approach. Control over the technical elements and their typing are important. Fundamental concept supported by ISA S95 standard is used as the basis for developing a model of integrated unit. Such concept helps creating a functional model which will represent a bridge between the business and process functions. It is, however, important to emphasise that ISA S95 standard does not embody an automated system which could be bought and would function as such. Yet it encompasses methods, process of work, thinking and communication which strive to help companies to reduce costs of implementation and development of integration. The basic requirement of the ERP and MES integration is the provision of a comprehensive information support of internal processes in the company. As mentioned hereinabove, the processes are usually divided into commercial and technical processes for which cooperation proves extremely important. The commercial process is characterized by the fact that most orders and call-offs are received with the help of software which facilitates computer data exchange. All orders and call-offs are stored in business information system and provide the company with forecasts, which need to be drawn up. An interface, enabling data exchange, is produced in the Microsoft Dynamics NAV business information system for the purposes of data exchange. For the purposes of data exchange an integration model (Figure 7) is produced, enabling two-way exchange of information. 


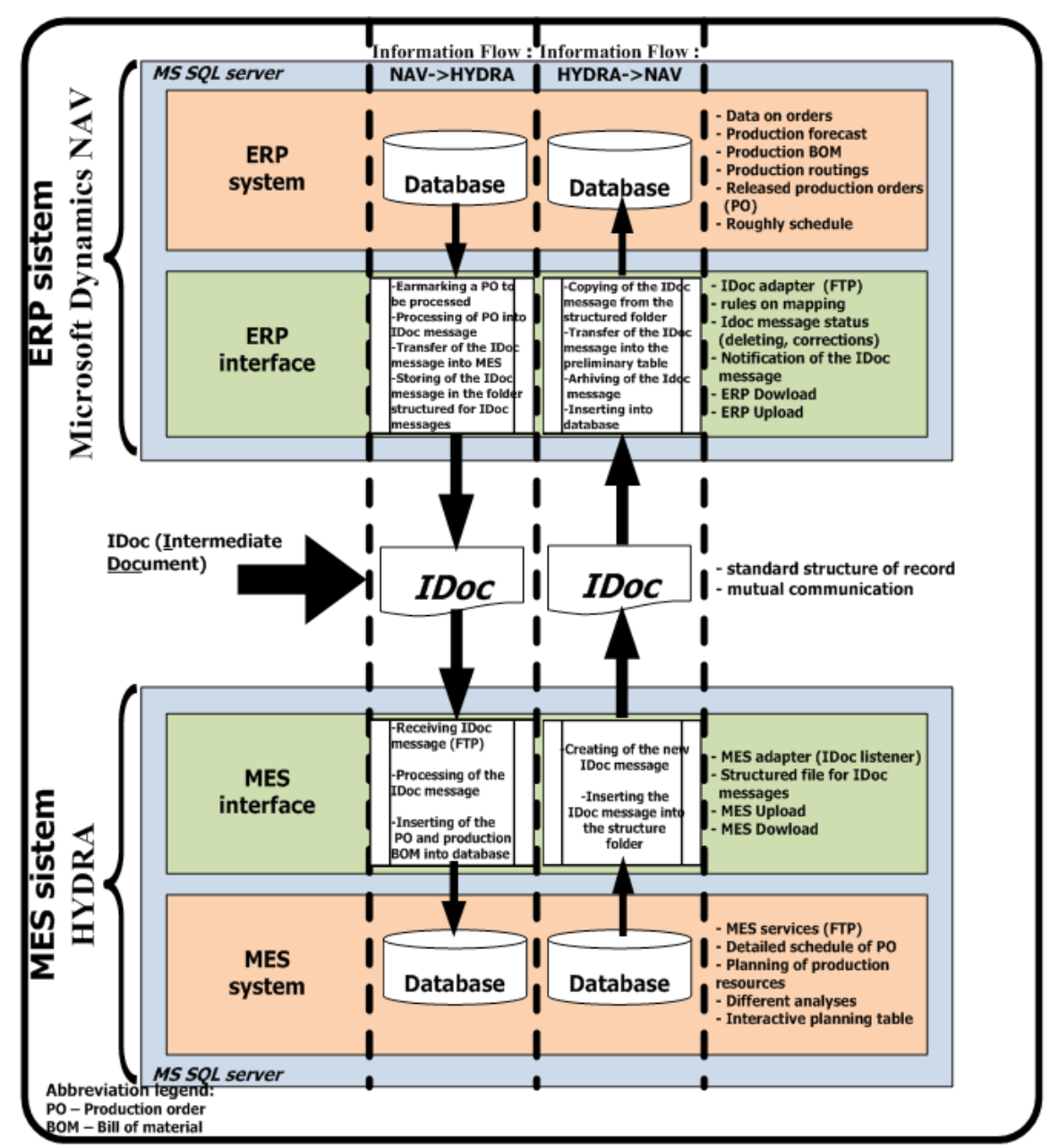

PROBLEMS

OF MANAGEMENT

IN THE $21^{\text {st }}$ CENTURY Volume 2, 2011

\section{Figure 7: Model of integration between the ERP and MES system.}

Integration model shown hereinabove is based on the developed interface which facilitates integration between the Microsoft Dynamics NAV ERP system and HYDRA MES system. Such interface is developed as an add-on to the Microsoft Dynamics NAV ERP system and represents the focus point of our research. The interface is actually a programme code which ensures cooperation of two databases, whereat specifics of both information systems are taken into consideration. The programming language C/AL (Client/Application Language) applied serves as a tool for creating business rules for stored data in tables, with interface having a function of translator, which converts the ERP Meta data into an IDoc file. Beside the basic function of transformation, the interface also converts data into a suitable form required by the information system (Microsoft Dynamics NAV ERP system and HYDRA MES system). As a matter of fact, the Meta data encompass orders, material requirements, production tallies, different production resources (workforce, machinery, devices, etc.) and manufacturing specifications necessary for successful management of production flow. The IDoc file or message represents a structured record enabling data exchange between two databases thus facilitating the integration of the ERP and MES systems.

A production procedure encompassing planned time of production is required for each order so as to monitor cost effectiveness of manufacturing activities. The planned time dimension is entered into the ERP system and encompasses planning from the start to finish. 
PROBLEMS OF MANAGEMENT IN THE $21^{\text {st }}$ CENTURY Volume 2, 2011

Each planned start and finish contains date and time of planned production. In such a way the production order is furnished with planned time attribute and represents the basis for the MES system. The cost dimension is primarily oriented towards costs arising from material needs and resources making a part of the production. On the basis of the time and cost dimensions described hereinabove, it may be concluded that each order requires unique identification number demonstrating the order's position throughout the project. Hereafter a concept of umber series is described, which was developed for the purposes of tracking order starting from its design and all the way through the business and production information system.

Table 1. Concept of number series.

\begin{tabular}{|c|c|c|c|}
\hline No. & Field Name & Filed Length & No. of positions \\
\hline 1 & Type of work order & 2 & $1-2$ \\
\hline 2 & Year & 2 & $3-4$ \\
\hline 3 & Reserved symbol & 1 & 5 \\
\hline 4 & Number of work order & 5 & $5-10$ \\
\hline 5 & Reserved symbol & 1 & 11 \\
\hline 6 & Designation of position & 3 & $12-14$ \\
\hline 7 & Number of position & 3 & $15-17$ \\
\hline 8 & Number of operation & 3 & $18-20$ \\
\hline
\end{tabular}

Table 2. Record of standardised number series.

\begin{tabular}{|c|c|c|c|c|c|c|c|c|}
\hline No .of positions & $\mathbf{1 - 2}$ & $\mathbf{3 - 4}$ & $\mathbf{5}$ & $\mathbf{5 - 1 0}$ & $\mathbf{1 1}$ & $\mathbf{1 2 - 1 4}$ & $\mathbf{1 5 - 1 7}$ & $\mathbf{1 8 - 2 0}$ \\
\hline Value & $\mathrm{RP}$ & 10 & - & 00001 & - & $\mathrm{POZ}$ & 007 & 010 \\
\hline Value & $\mathrm{RP}$ & 10 & - & 00001 & - & $\mathrm{E} 01$ & 007 & 010 \\
\hline Value & $\mathrm{DN}$ & 10 & - & 00001 & - & $\mathrm{POZ}$ & 001 & 010 \\
\hline
\end{tabular}

An Example of Standardized Number Series for Transfer into the MES System

Final result of number series which is transferred into the MES system is as follows:

- RP10-00001-POZ007010,

- RP10-00001-E01007010,

- DN10-00001-POZ001010.

\section{Discussion}

Modern manufacturing companies need to establish an efficient strategic cooperation with the purpose of improving their competitiveness on the market (Humphreys et al., 2001). In the previous decade the attention was focused on the optimisation of production processes, while now the time is right to bring inline the supply chain from the suppliers to customers (Abele et al., 2006). The optimisation of supply chain may be improved with the computerisation of operations since possibilities for system improvements and simplification are thus gained. A good information system brings a number of cumulative information on product demand and company's capacities. Since the exchange of information among partners in the supply chain influences positively on the resource planning, a company can improve control of its processes. Tracking customer's order throughout the entire supply chain and at the same time, monitoring costs as per individual dimension is made possible with the demonstrated model of integration and the concept of number series. 


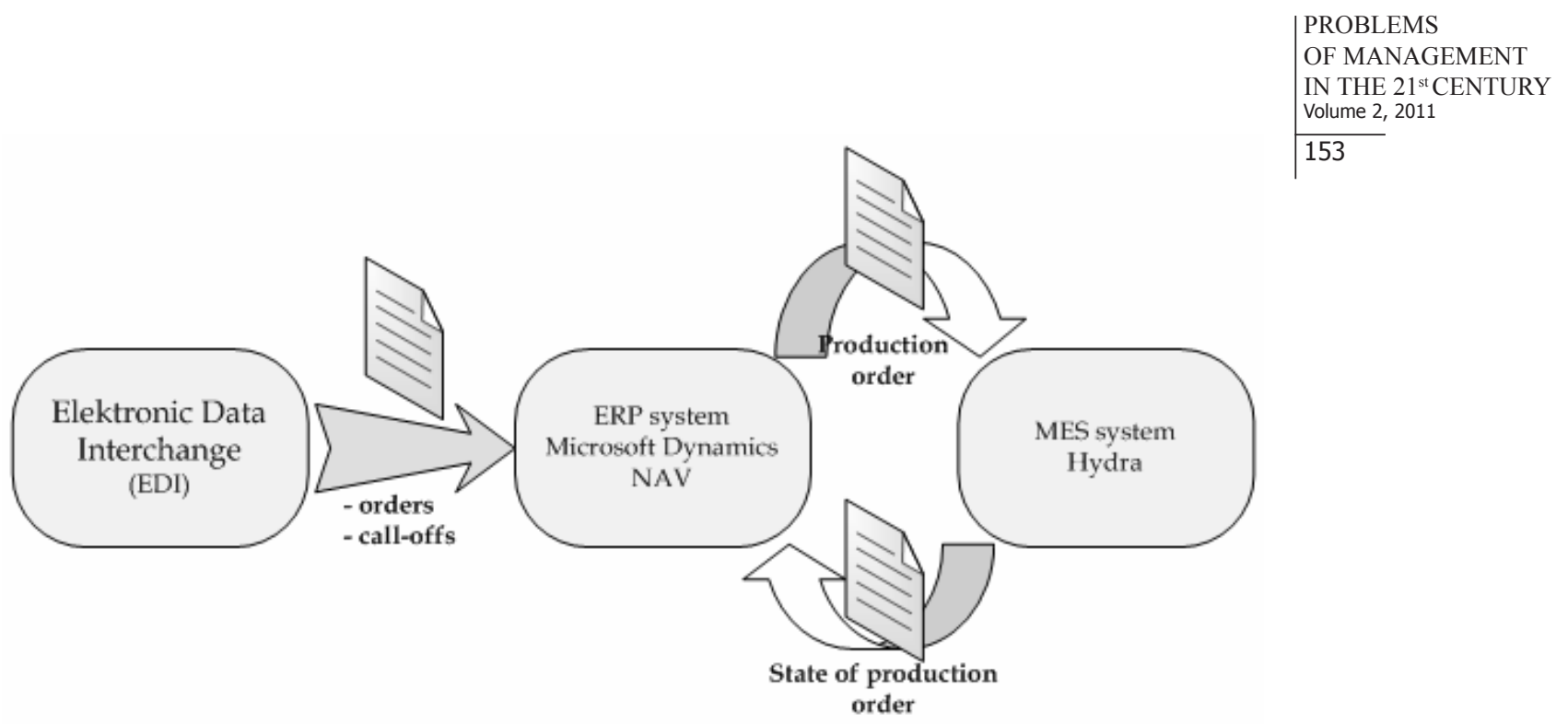

Figure 8: Commercial process monitoring.

As evident in (Figure 8) calculation of basic production planning and planning of material requirements is performed on the basis of a forecast. Based on the calculated plan, sales orders (intended for destocking) are drawn up. At the same time work orders are drawn up, which are then transferred into the production information system. A loopback serves for reporting on the state of work orders. It proves essential for the technical process that the development tallies, drawn up on the basis of one of the CAD/CAM/CAE systems, are converted into the business information system (Figure 9). Each development tally contains component parts of tools presented in the ERP system as a semi-manufactured product described with the status of ordering or status of work order.

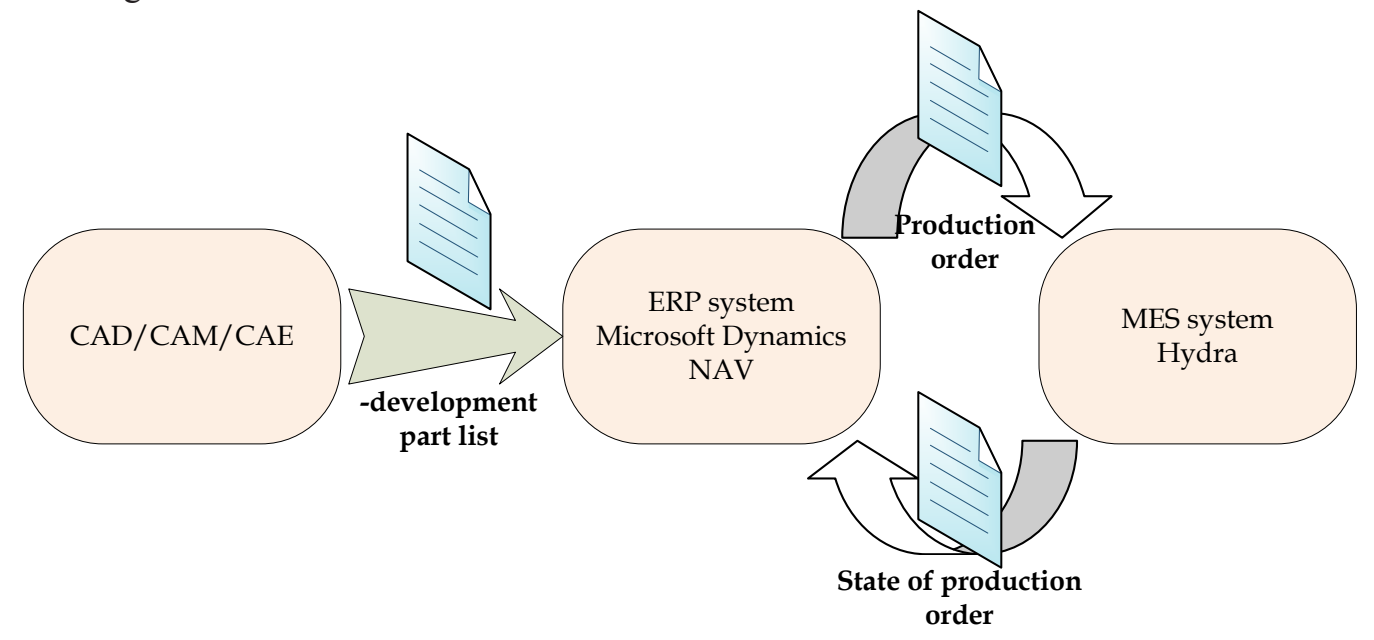

Figure 9: Technical process monitoring.

On the basis of statuses of each semi-manufactured product a calculation of material requirements and cooperation is performed. The calculation serves as the basis for producing work orders (cooperation and material requirements). This is followed by technology processing, which actually represents development of technical procedures and work instructions. Production of work orders follows, which are also transferred into the MES system. A loopback serves for reporting on the state of work orders or state of the production of semi-manufactured 
PROBLEMS

OF MANAGEMENT

IN THE $21^{\text {st }}$ CENTURY

Volume 2, 2011

154

product. It is, however, necessary to emphasise that the technical process envisages the control of data on numerous levels, which includes the production of electrodes for a particular semimanufactured product and cooperation.

Steps of further researches should focus on collaborative computing, composed of technologies and techniques which at the same time facilitate cooperation among people, software and hardware. Numerous known technologies, which contribute to the appearance of this new paradigm in computing, allow large and small companies to join computing in the clouds. Services in the clouds facilitate interoperability of database and represent a part of information infrastructure which enables companies and organisations to move or integrate a particular quantity of data onto the location in the cloud. Question thus arises on how to improve cooperation among companies which use different software.

\section{Conclusions}

On the basis of our research a conclusion is made that there are no standard application interfaces yet only standard records, which allow integration, serve for communication. Undoubtedly, the IDoc message represents one of these standard records since it enables data exchange between two databases. The purpose of IDoc message is to integrate business and production information systems which operate independently. At the same time, we establish that the data exchange is a two-way process for which an integration model demonstrated in Figure 7 is developed. The aforementioned model of integration encompasses developed application interface which facilitates data exchange between the ERP and MES system. In order to ensure traceability of the information flow, a concept of number series is developed, enabling monitoring of order from the start to its exploitation.

Integration facilitates an efficient planning of manufacturing processes which proves necessary for the optimisation of the entire supply chain. Demonstrated integration model between the ERP and MES system brings as follows:

- monitoring of the market and forecasting needs,

- immediate consideration of resources in the planning process,

- checking availability in real time,

- $\quad$ simulation of production system response and support in decision-making process.

Integration of business and process information via IDoc message enables different departments to plan their resources simultaneously yet ensure their independent operation. The purpose of managing business processes is a simultaneous planning of the entire chain, whereat all involved develop the plan together, namely with the purpose to reduce stocks and set more competitive prices of their products.

\section{References}

Abele, E., Elzenheimer, J., Liebeck, T., Meyer, T. (2006), Reconfigurable Manufacturing Systems and Transformable Factories. In. A.I. Dashchenko(Ed.), Globalization and Decentralization of Manufacturing, (pp. 4-5). New York: Springer.

Beheshti, H. M. (2006). What managers should know about ERP/ERP II. Management Research News, 29(4), 184-193.

Campos. J. G., Miguez, L. R. (2011). Standard process monitoring and traceability programming in collaborative CAD/CAM/CNC manufacturing scenarios. Computers in Industry, 62(3), 311-322. 
Simon OMAN. Application of Intermediate Document Message in the Process of Enterprise Resource Planning and Manufacturing Executing System Integration

Djassemi, M. (2009). Emergence of multitasking machining systems: applications and best selection practices. Journal of Manufacturing Technology Management, 20(1), 130-142.

Harjunkoski, I., Nyström, R. Horch, A. (2009). Integration of scheduling and control-Theory or practice? Computers and Chemical Engineerin, 33(12), 1909-1918.

Hori, M., Kawamura, T., Okano, A. (1999, October). OpenMES: scalable manufacturing execution framework based on distributed object computing. Paper presented at the conference of the IEEE SMC '99 Conference Proceedings, Tokyo, Japan.

Humphreys, P. K., Lai, M. K., Sculli, D. (2001). An Inter-Organizational Information System for Supply Chain Management, International Journal of Production Economics, 70(3), 245-255.

Kakouris, A. P., Polychronopoulos, G. (2005). Enterprise Resource Planning (ERP) System: An Effective Tool for Production Management. Management Research News, 28(6), 66-78.

Kirsilä, J., Hellström, M., Wikström K. (2007). Integration as a project management concept: A study of the commissioning process in industrial deliveries. International Journal of Project Management, 25(7), 714-721.

Kletti, J. (2007). Manufacturing Execution System - MES, New York: Springer.

Lai, J. Chen, W. (2009). Measuring e-business dependability: The employee perspective. The Journal of Systems and Software, 82(6), 1046-1055.

Liu, H., Barrar, P. (2009). Performance implications of strategy-technology connections: an emperical examination. Journal of Manufacturing Technology Management, 20(1), 52-73.

Marnewick, C., Labuschagne, L. (2005). A conceptual model for enterprise resource planning (ERP). Information Management \& Computer Security, 13(2), 144-155.

Mertins, K., Rabe, M., Gocev, P. (2008). Lean Business System And Beyond. In. T. Koch (Ed.),

Integration of Factory Planning and ERP/MES Systems: Adaptive Simulation Models, (vol.257), (pp.

185-193). Boston: Springer.

Metaxiotis, K. (2009). Exploring the rationales for ERP and knowledge management integration in

SMEs. Journal of Enterprise Information Management, 22(1-2), 51-62.

Møller, C. (2005). ERP II: A conceptual framework for next-generation enterprise systems? Journal of Enterprise Information Management, 18(4), 483-497.

Panetto H., Molina, A. (2008). Enterprise integration and interoperability in manufacturing systems: Trends and issues. Computers in Industry, 59(7), 641-646.

Patel, S. C., Sanyal, P. (2008). Securing SCADA systems. Information Management \& Computer Security, $16(4), 398-414$.

Sammon, D., Adam, F. (2005). Towards a model of organisational prerequisites for enterprise-wide systems integration: Examining ERP and data warehousing. Journal of Enterprise Information Management, 18(4), 458-470. 
PROBLEMS

OF MANAGEMENT

IN THE $21^{\text {st }}$ CENTURY

Volume 2, 2011

156

Scholten, B. (2011). De greens tussen MES en SCAD. Automatie, 6. Retrieved 15/9/2011, from http://

www.biancascholten.info/articles.html.

Stadtler, H. (2004). Supply chain management and advanced planning - basics, overview and challenges. European Journal of Operational Research, 163(3), 575-588.

Tarn, J. M., Yen, D. C., Marcus, Beaumont, M. (2002). Exploring the rationales for ERP and SCM integration. Industrial Management \& Data Systems, 102(1), 26-34.

Themistocleous, M., Irani, Z., O’Keefe, R. M. (2001): ERP and application integration: Exploratory survey. Business Process Management Journal, 7(3), 195-204.

Thomas Gulledge, T. (2006). What is integration? Industrial Management \& Data Systems, 106(1), 520 .

Wicks, M. N., R. G., Dewar, R. G. (2007). A new research agenda for tool integration. The Journal of Systems and Software, 80(9), 1569-1585.

Zhao, X., Huo, B., Willem, Selen, W., Hoi Yan Yeung, J. (2011). The impact of internal integration and relationship commitment on external integration. Journal of Operations Management, 29(1-2), 17-32.

Zhou, B., Wang, S., Xi, L. (2005). Data model for manufacturing execution system. Journal of Manufacturing technology Management, 16(8), 909-935.

Advised by Andrej Kovačič, University of Ljubljana, Slovenia

Received: August 30, 2011

Accepted: November 02, 2011

Simon Oman

Organisation and Management Specialist, IT Manager,

Polycom Škofja Loka, Poljane nad Škofjo Loko 76, 4223 Poljane, Slovenia.

E-mail: simon.oman@polycom.si

Website: http://www.polycom.si/ 